\title{
Local control of mammary involution: Is stanniocalcin-1 involved? ${ }^{1}$
}

\author{
G. Tremblay, ${ }^{*}$ P. Bernier-Dodier, ${ }^{*}$ L. Delbecchi, $\dagger^{2}$ G. F. Wagner, $\ddagger$ B. G. Talbot, ${ }^{*}$ and P. Lacasse $\dagger^{3}$ \\ *Département de Biologie, Faculté des Sciences, Université de Sherbrooke, Sherbrooke, Quebec, Canada J1K 2R1 \\ †Dairy and Swine Research and Development Centre, Agriculture and Agri-Food Canada, PO Box 90 STN Lennoxville, Sherbrooke, Quebec, \\ Canada J1M 1 Z3 \\ ‡Department of Physiology and Pharmacology, Faculty of Medicine and Dentistry, The University of Western Ontario, London, Ontario, \\ Canada N6A 5C1
}

\begin{abstract}
There is considerable evidence to indicate the existence of local control of mammary gland involution, but the exact nature of this control has yet to be defined. Stanniocalcin-1 (STC-1) is a newly discovered mammalian hormone that seems involved in the lactation process and may be implicated in the control of involution. As a first step in investigating this hypothesis, the change in STC-1 levels in milk and serum was measured during drying off. Nine Holstein cows in late lactation were milked twice daily on half the gland, while the other half was left unmilked for a 14-d period. Milk and blood samples and mammary biopsies were taken on $\mathrm{d}-7,1,2,7$, and 14 relative to the onset of the nonmilking period. The concentrations of STC-1 in serum and milk were determined by RIA. The albumin concentration and proteinase activity of the milk were determined. Apoptosis of the mammary epithelium was quantified by terminal deoxynucleotidyl transferasemediated dUTP nick-end labeling assay. Finally, the effects of milk on cellular activity and apoptosis were tested in vitro on mammary epithelial cells by measuring the turnover of tetrazolium salts and by counting the terminal deoxynucleotidyl transferase-mediated dUTP nick-end labeling-positive cells. The drying off of 2 quarters increased the milk production of the quarters that were milked by $30 \%$. Milk proteinase activity and BSA and STC-1 concentrations increased in the nonmilked quarters, but remained unchanged in the milked quarters. Moreover, at d 2, the apoptotic rate of the mammary cells was higher in the nonmilked quarters than in the milked quarters $(0.22 \pm 0.04$ vs. $0.07 \pm$ $0.04 \%$, respectively). Finally, in vitro experimentation demonstrated that mammary epithelial cells cultured in the presence of milk from involuting quarters had 3-fold
\end{abstract}

Received August 20, 2008.

Accepted December 17, 2008.

${ }^{1}$ Dairy and Swine R\&D Centre contribution no. 985.

${ }^{2}$ Deceased.

${ }^{3}$ Corresponding author: lacassep@agr.gc.ca more apoptotic cells as compared with those cultured in milk from the milked quarters at d 14 . The metabolic rate was reduced by $14.6 \%$ for milk from d 7 and $23.6 \%$ for milk from d 14. Interestingly, the metabolic rate was negatively correlated with the STC-1 concentration in milk $(\mathrm{r}=-0.65)$. This study shows for the first time that STC-1 in milk is increased following milk stasis, although its exact role in the involution process remains to be clarified.

Key words: tight junction, proteinase, apoptosis, dairy cow

\section{INTRODUCTION}

Forced involution occurs when milk is no longer removed from the mammary gland. In dairy cattle, the mechanism of regulation and the factors implicated in this phenomenon are still poorly understood. In the mouse, forced involution occurs in 2 distinct phases (Lund et al., 1996) leading to mammary regression. The first phase is characterized by apoptosis of mammary epithelial cells, while the second is characterized by biosynthesis of proteinases, leading to extracellular matrix degradation and intensive tissue remodeling. Based on proteinase expression data, Rabot et al. (2007) suggested that bovine mammary involution is divided into 2 steps. Still, involution in dairy cattle demonstrates more changes in secretory activities than in tissue regression, and these changes are more subtle. First, after about $18 \mathrm{~h}$ of milk stasis, there is an increase in the permeability of mammary tight junctions (TJ; Stelwagen et al., 1997) as demonstrated by the presence in blood of milk-specific components. The increases in apoptosis were transitory for the first days following drying off (Sorensen et al. 2006). In cows, by contrast, the dry period between lactation entailed no net loss of mammary cells (Capuco et al. 1997), even though proteinases were increased following milk stasis. However, the bovine proteolysis phase is not well understood and is not as significant as that of the rodents' because mammary alveolar structures in cows are conserved up to $60 \mathrm{~d}$ after the cessation of milking (Capuco et al., 1997). Thus, 
the exact nature and contributions of the proteinases to bovine mammary involution are still unknown. Despite several studies of bovine mammary gland involution, crucial pieces of information are missing which appear necessary to connect lactation and involution events and to explain how they are regulated.

Some gaps in the understanding of the bovine mammary gland involution could perhaps be filled by a better characterization of the newly discovered mammalian factor, stanniocalcin-1 (STC-1). This is a hormone that was first identified in fish and recently discovered in mammals (Wagner et al., 1995). In euryhaline teleost fish adapted to fresh water, 2 hormones dominate calcium homeostasis: prolactin and STC. Stanniocalcin is released into the blood following hypercalcemia to decrease gill calcium uptake and increase phosphate intake by the gut. To balance this, prolactin exerts a calcitropic action (Flik et al., 1994). In mammals, STC-1 functions as a calcium modulator (Madsen et al., 1998); however, it is involved in other physiological processes. Studies in mice suggest that STC-1 is implicated in both gestation and lactation processes (Deol et al., 2000). In that species, the ovaries expressed more STC-1 than any other organ (Varghese et al., 1998). During gestation and lactation, STC-1 expression in the ovary increased and became detectable in blood (Deol et al., 2000). Moreover, some of this ovarian STC-1 was targeted to the milk-producing epithelia of the mammary gland (Hasilo et al., 2005). Also in mice, it was demonstrated that wild-type pups suffered growth retardation when fed by transgenic mothers over-expressing human STC-1 (Varghese et al., 2002). Finally, passive immunization against STC-1 induced an alteration in the composition of the milk and caused growth retardation (Zaidi et al., 2006). It appears that STC-1 is important for the regulation of lactation in mice although its precise role is not yet clear.

Very few studies have investigated the STC-1 contained in milk during bovine lactation. Delbecchi et al. (2005) demonstrated that injections of 17ß-estradiol to lactating cows, while reducing milk production, increased the expression of STC-1 by the mammary gland and increased the levels of STC-1 in milk. This was the first report of STC-1 in bovine milk and the first demonstration of STC-1 gene expression in the bovine mammary gland. Later, Miller et al. (2006) measured STC-1 levels in cow milk during an entire lactation period. They found that STC-1 concentrations in milk increased as lactation progressed. These studies suggest that STC-1 is involved in the involution process. The discovery of STC-1 in bovine milk and its possible role in involution indicates the need to analyze the evolution of STC-1 concentrations at drying off, as well as the possible function of STC-1 as an inducer of involu- tion. Consequently, this study investigated the changes in milk STC-1 concentrations during bovine mammary gland involution caused by the unilateral cessation of milking.

\section{MATERIALS AND METHODS}

\section{Animals and Experimental Procedures}

The experiment was conducted in accordance with the guidelines of the Canadian Council on Animal Care. Cows were housed at the Dairy and Swine Research and Development Centre of Agriculture and Agri-Food Canada (Sherbrooke, QC, Canada). Ten Holstein cows, 5 primiparous and 5 multiparous, with an average of $120 \mathrm{~d}$ of gestation and 225 DIM, underwent the following treatment: On d 0, the right forequarter and left hindquarter were dried off, while the left forequarter and right hindquarter continued to be milked twice daily for $14 \mathrm{~d}$. Dried quarters were sealed with DryFlex (DeLaval International AB, Tumba, Sweden). One primiparous cow was removed from the experiment because of digestive problems. Milk production was quantified by weighing the milk from each quarter. Milk and blood samples and mammary biopsies were taken on $\mathrm{d}$ $-7,1,2,7$, and 14 relative to the onset of the nonmilking period. Milk concentrations of lactose, protein, fat, and SCC were determined in a commercial laboratory (Valacta Inc., Ste-Anne-de-Bellevue, QC, Canada). Blood samples were taken from the tail vein, incubated overnight at $4^{\circ} \mathrm{C}$, and centrifuged at $4,000 \times g$ for 15 min at $4^{\circ} \mathrm{C}$. Serum was obtained and frozen at $-20^{\circ} \mathrm{C}$. Milk samples $(50 \mathrm{~mL})$ were collected manually from the forequarters, skimmed by centrifugation (15 min at $1,000 \times g, 4^{\circ} \mathrm{C}$ ), and frozen. Mammary tissue biopsies were taken from the hindquarters as described (Miller et al., 2006). Biopsy sites were chosen to avoid areas of the gland that were previously harvested. Biopsies were immediately cut into several pieces, which were either snap frozen in liquid nitrogen (200-mg pieces) or fixed in 10\% formalin (20 mg pieces). Restless cows received an i.m. injection of $10 \mathrm{mg}$ of acepromazine maleate (Atravet, Wyeth Animal Health, Guelph, ON, Canada) a few minutes before each biopsy.

\section{Determination of Milk Gelatinase Activity}

Zymography was performed according to Raser et al. (1995). Briefly, $2.5 \mu \mathrm{L}$ of skimmed milk was diluted in $7.5 \mu \mathrm{L}$ of water and mixed 1:1 with sample loading buffer $(0.125 M$ Tris. $\mathrm{HCl} \mathrm{pH}$ 6.8, $4 \%$ SDS, $0.005 \%$ bromophenol blue, and 20\% glycerol). Samples were separated on $12.8 \%$ polyacrylamide gels containing 2 $\mathrm{mg}$ of gelatine/mL using a Mini Protean II apparatus 
(Bio-Rad, Mississauga, ON, Canada) as described by Lauzon et al. (2006), except that samples were run at $150 \mathrm{~V}$ for $150 \mathrm{~min}$. After PAGE, the gels were removed from the cast and washed twice with gentle shaking for $30 \mathrm{~min}$ in $100 \mathrm{~mL}$ of $2.5 \%$ Triton X-100. The washing buffer was replaced with developing buffer $(50 \mathrm{mM}$ Tris.base, $200 \mathrm{mM} \mathrm{NaCl}, 5 \mathrm{mM} \mathrm{CaCl}$, and $0.02 \%$ Brij $35)$ for $30 \mathrm{~min}$. The gels were incubated for $48 \mathrm{~h}$ at $37^{\circ} \mathrm{C}$ in fresh developing buffer before being stained by soaking in a solution of $0.5 \%$ Coomassie Blue R-250, $40 \%$ methanol, and $10 \%$ acetic acid. After destaining in a solution of $50 \%$ methanol and $10 \%$ acetic acid, pictures of the gels were taken using a FluorChem SP imaging system (Alpha Innotech, San Leandro, CA). Values were determined from the integrated density of bands (pixel intensity $\times$ area) as described by Kleiner and Stetler-Stevenson (1994). Molecular weight and band density were analyzed with AlphaEase FC software (Alpha Innotech).

\section{Evaluation of Milk BSA}

The concentration of BSA in milk was determined as described previously (Bouchard et al., 1999). Briefly, 50 $\mu \mathrm{L}$ of skimmed milk was added to $500 \mu \mathrm{L}$ of a solution containing 1 vol of $1.2 \mathrm{mM}$ bromocresol green dissolved in $5 \mathrm{~m} M \mathrm{NaOH}$ and $3 \mathrm{vol}$ of $0.2 M$ succinic acid, $\mathrm{pH} 4.0$, with Brij 35 added to a final concentration of $0.8 \%$ ( $\mathrm{vol} /$ vol). Samples were mixed by inversion and centrifuged at room temperature for $10 \mathrm{~min}$ at 3,000 $\times \mathrm{g}$. Supernatants were removed and $150 \mu \mathrm{L}$ was added to a 96 -well microplate before reading at $640 \mathrm{~nm}$ on a SpectraMax 250 plate reader (Molecular Devices, Sunnyvale, CA).

\section{Evaluation of IGF-I and STC-1}

Milk IGF-I was quantified by RIA as described by Abribat et al. (1993) for serum. Milk and serum concentrations of STC-1 were determined by RIA as described by Niu et al. (2000).

\section{In Situ Apoptosis Detection}

Small pieces of mammary biopsies (20 mg) were fixed in $10 \%$ formalin for $1 \mathrm{~h}$, then transferred to a fresh formalin solution for $18 \mathrm{~h}$. Fixed tissues were stored in $70 \%$ ethanol at $4^{\circ} \mathrm{C}$ until processing. Paraffin inclusion, dewaxing, and hydration were performed according to standard techniques, except that xylene was replaced by SafeClear (Fisher Scientific, Pittsburgh, PA), and 5 $\mu \mathrm{m}$ thick tissue sections were generated using a microtome. Apoptosis was detected by terminal deoxynucleotidyl transferase-mediated dUTP nick-end labeling
(TUNEL) assay kit (DeadEnd Colorimetric TUNEL System) from the Promega Corporation (Madison, WI). Following detection, cell nuclei were counterstained with methyl green. Pictures were taken using an Axio Imager M1 microscope (Carl Zeiss AG Light Microscopy, Göttingen, Germany) and analysis was performed using ImageJ software (National Institutes of Health, Bethesda, MD).

\section{Evaluation of the Effect of Milk Samples on Apoptosis and Metabolic Rate of Mammary Epithelial Cells in Culture}

Milk samples harvested from involuting quarters on $\mathrm{d}$ $-7,2,7$, and 14 (relative to the onset of the nonmilking period) and from milked quarters at d 14 were tested on mammary epithelial cells (MAC-T cells) for their capacity to reduce cellular metabolism. The experiment was carried out as follows: MAC-T cells were grown to confluence in 96-well plates in Dubelcco's Modified Eagle's Medium/F12 medium containing $4.5 \mathrm{~g}$ of Dglucose/L, 5\% fetal bovine serum (Gibco Invitrogen Cell Culture, Carlsbad, CA), 100 IU of penicillin/mL, $10 \mu \mathrm{g}$ of streptomycin/mL, and $250 \mathrm{ng}$ of amphoterycin $\mathrm{B} / \mathrm{mL}$ (Wisent Inc., Saint-Jean-Baptiste de Rouville, QC). Confluent cells were washed with Hanks' balanced salt solution (HBSS) and incubated for $10 \mathrm{~h}$ in culture medium containing milk at a final concentration of $10 \%$. Coloration with tetrazolium salt (XTT; 23-bis(2-methoxy-4-nitro-5-sulfophenyl)-2H-tetrazolium-5carboxanilide; Invitrogen Molecular Probes, Eugene, OR) was performed by removing the medium and, after an HBSS wash, by adding $100 \mu \mathrm{L}$ of XTT solution for $30 \mathrm{~min}$ at room temperature in the dark (Dodier and Piche, 2006). The turnover of XTT was quantified by reading the absorbance at $450 \mathrm{~nm}$ on a SpectraMax 250 plate reader (Molecular Devices). The metabolic rate was defined as the relative absorbance of treated versus untreated cells, calculated in percent.

The capacity of milk samples to induce apoptosis of MAC-T cells was tested on pooled milk from involuting quarters on d 14 or milked quarters at the same day. Cells were grown in 6-well plates and incubated for $10 \mathrm{~h}$ with milk under the same conditions as described. Following incubation, cells were harvested with trypsin/ EDTA, centrifuged for $10 \mathrm{~min}$ at $300 \times g$ at room temperature and re-suspended with HBSS. Cells were air-dried on Fisherbrand Superfrost Plus microscope slides (Thermo Fisher Scientific, Waltham, MA) and fixed for $25 \mathrm{~min}$ in $10 \%$ formalin. Detection by TUNEL assay was done according to manufacturer recommendations (DeadEnd Colorimetric TUNEL System); the nucleus was counterstained with methyl green. Pictures 


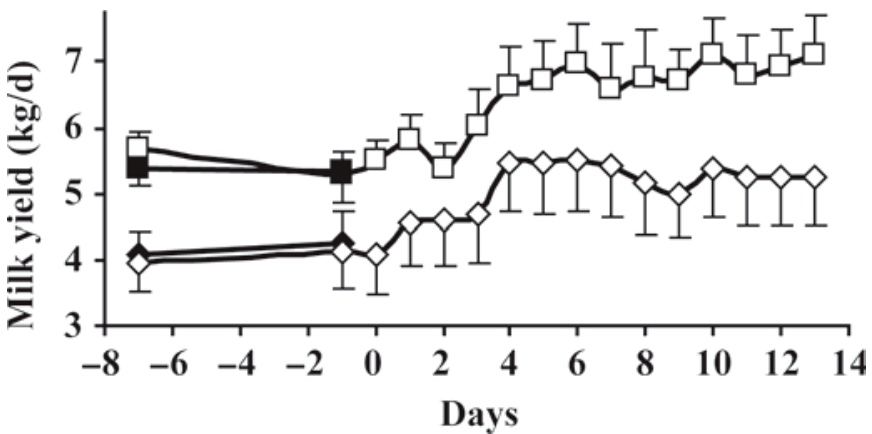

Figure 1. Effect of unilateral milking on milk yield. Milked quarters: left forequarters, $\diamond$, and right hindquarters, $\square$; nonmilked quarters: right forequarters, $\bullet$, and left hindquarters, $\mathbf{a}$. Value 0 on time scale refers to drying off. Data are presented as unadjusted means \pm SEM.

were taken using a Nikon 50i microscope (Nikon, Tokyo, Japan) and analysis was performed using Image J software.

\section{Statistical Analysis}

Statistical analysis for milk production, proteinase activity, milk composition, TUNEL, IGF-I, BSA, and STC-1 in serum and milk was performed using the Mixed procedure of SAS (SAS Institute, Cary, NC) with repeated measurements. Because proteinase activity and BSA data were not normally distributed, analysis was performed on $\log _{10}$ transformed values. For the same reason, correlations were determined using the Spearman correlation technique. Analysis of metabolic rates was done with the Student's t-test using a paired data option with the Bonferroni technique to fix the significance level to 0.005 for this test. No significant differences were found between multiparous and primiparous cows among all measured traits. Therefore, parity was not included in the final model.

\section{RESULTS}

As shown in Figure 1, milk production from left quarters and right quarters was similar before the onset of unilateral milking. After the cessation of milking of the right forequarters and the left hindquarters, milk production from the left forequarters and right hindquarters increased to reach $130 \%$ of pre-treatment levels by d $14(P<0.0001)$. Drying off of 2 quarters induced a decrease $(P<0.05)$ in fat and protein concentrations in the milk of milked quarters on the first day following drying off (data not shown).

Up to d 2, the BSA concentrations in milk from milked and nonmilked quarters were low and similar (Figure

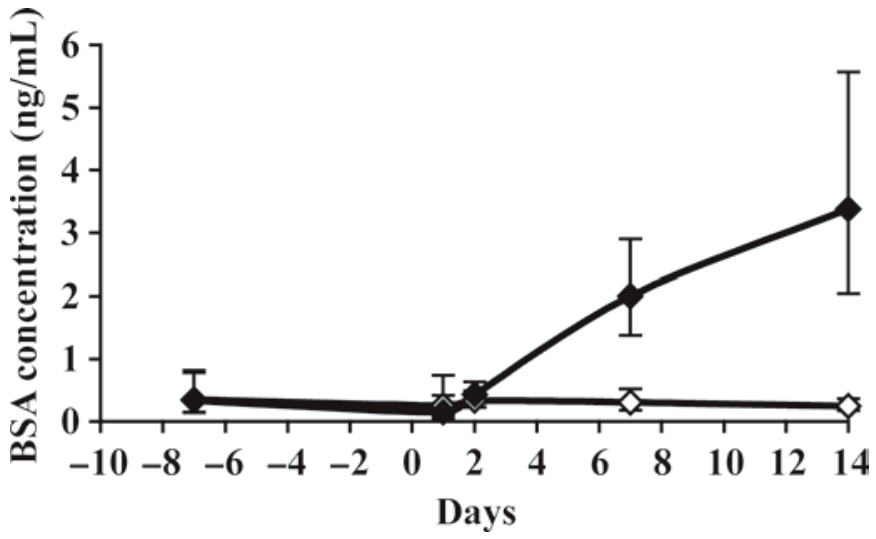

Figure 2. Effect of unilateral milking on milk BSA concentration. nonmilked quarters: $\bullet$, milked quarters: $\diamond$. Value 0 on time scale refers to drying off. Data were $\log _{10}$ transformed before statistical analysis and are presented as the antilog values of the calculated means with superior and inferior confidence bounds.

2). After d 2, these BSA concentrations increased in the milk from nonmilked quarters $(P<0.0001)$, whereas they remained unchanged in the milk from milked quarters.

An analysis of milk on gelatine zymograms revealed 2 patterns of proteolytic activity, depending on whether the milk came from milked or nonmilked quarters. Two main proteinases were present among all cows (Figure $3 \mathrm{~A})$. The apparent molecular weights of these proteinases were 68 and $110 \mathrm{kDa}$, which, according to Raulo et al. (2002) correspond to matrix metalloproteinases (MMP) MMP-2 and MMP-9, respectively. Milk from nonmilked quarters had an increase in MMP-2 activity $(P<0.005)$ on $\mathrm{d} 7$ and $\mathrm{d} 14$, whereas activity remained unchanged in milk from milked quarters. Similarly, the activity of MMP-9 in milk from nonmilked quarters increased $(P<0.0001)$, whereas milk from milked quarters presented little or no activity during the same period. Total proteinase activity in milk from milked quarters remained unchanged during the treatment, while an increase was detectable in milk from nonmilked quarters $(P<0.0001$; Figure 3B).

The concentration of milk IGF-I was similar between the quarters before the onset of treatment. After d 2, IGF-I concentration increased in nonmilked quarters, but remained unchanged in milked quarters $(P<0.005$; Figure 4).

The concentration of STC-1 in serum increased by $25 \%$ from d -7 to d $14(P<0.01$; Figure 5$)$. Milk STC-1 increased by $223 \%$ from d 2 to d $14(P<0.001)$ in nonmilked quarters, ultimately reaching $9 \mathrm{ng} / \mathrm{mL}$. Stanniocalcin-1 concentrations in milk from milked quarters did not change across the entire treatment period. 
A)

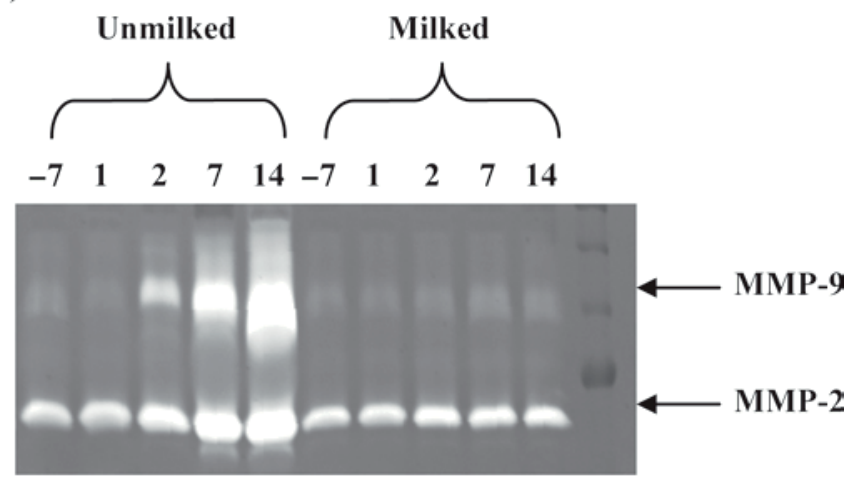

B)

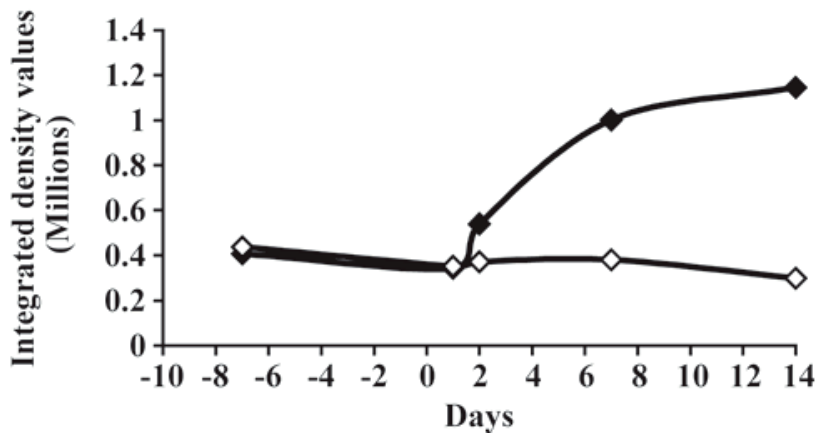

Figure 3. Total gelatinase activity measured in milk. A) Typical results obtained for $1 \mathrm{cow}$. Sample number relates to days from drying off. B) Total gelatinase activity measured on gelatin zymograms by densitometric analysis. Nonmilked quarters: $\bullet$, milked quarters: $\diamond$ Value 0 on time scale refers to drying off. Data are presented as least squares means (SEM < 0.016). Molecular weight standard is Precision Plus all blue from Bio-Rad (Mississauga, ON, Canada).

Detection of apoptotic cells in mammary biopsies showed a transitory increase of apoptosis on d $2(P<$ 0.05 ) following milk stasis (Figure 6). The effect of different samples of milk obtained from milked and nonmilked quarters on the metabolic rate and apoptosis of MAC-T cells in culture was investigated. By measuring the turnover of XTT, milk from nonmilked quarters on $\mathrm{d}-7$ and $\mathrm{d} 2$ gave results similar to control medium without milk (not shown) or to milk from milked quarters on d 14 (Figure 7). Milk from nonmilked quarters reduced the metabolic rate by $15 \%$ for $\mathrm{d} 7(P<0.0001)$ and $24 \%$ for d $14(P<0.005)$ compared with milked quarters at d 14. By TUNEL assay, pooled milk from involuting quarters at $\mathrm{d} 14$ increased the number of apoptotic cells $(P<0.005)$ by 3 -fold compared with milked quarters. Cells incubated in medium without milk were no different from milked quarters.

Further statistical analysis revealed a correlation between STC-1 concentrations in milk, the BSA concentration $(\mathrm{r}=0.77 ; P<0.001)$, and proteinase activity $(\mathrm{r}$
$=0.50 ; P<0.001)$. The correlation between STC-1 and proteinases was mainly driven by MMP-9 ( $\mathrm{r}=0.61$; $P<0.001)$. Negative correlations were found between the metabolic rate of cells and the STC-1 content of milk $(\mathrm{r}=-0.65 ; P<0.001)$. These correlations are summarized in Table 1.

\section{DISCUSSION}

We used a differential milking model to induce involution in 2 quarters in lactating cows with the goal of evaluating the changes in STC-1 concentrations at this physiological stage. This model enabled us to study, in the same animal, the induction of involution by milk stasis while the other quarters were still producing milk. We found that BSA concentrations increased from d 2 in the dried-off quarter, while remaining unchanged in the control quarters. We observed that proteolytic activity increased only in the dried-off quarters beginning $2 \mathrm{~d}$ after cessation of milking. These findings support previous reports (Wheelock et al., 1967). Apoptosis increased in nonmilked quarters $2 \mathrm{~d}$ after drying off and then returned to the rate of the milked quarters. This transitory increase in apoptosis following drying off was reported by Sorensen et al. (2006). These results enable us to posit a time course of the involution process induced by local factors. We conclude that, $2 \mathrm{~d}$ after the last milking, the involution process has begun. This supports Hamann and Gyodi (1994), who found, using a differential milking model, that a $2 \mathrm{~d}$ dryingoff period did not affect milk production for the 12 d subsequently, while a 4-d drying-off period reduced milk production for that same subsequent period. A correlation was found between STC-1 concentrations in milk and the BSA $(\mathrm{r}=0.77)$ concentration or proteolytic activity $(\mathrm{r}=0.50)$. Correlations between STC-1 and these involution markers suggest that STC-1 levels in cow milk increase in response to milk stasis, which

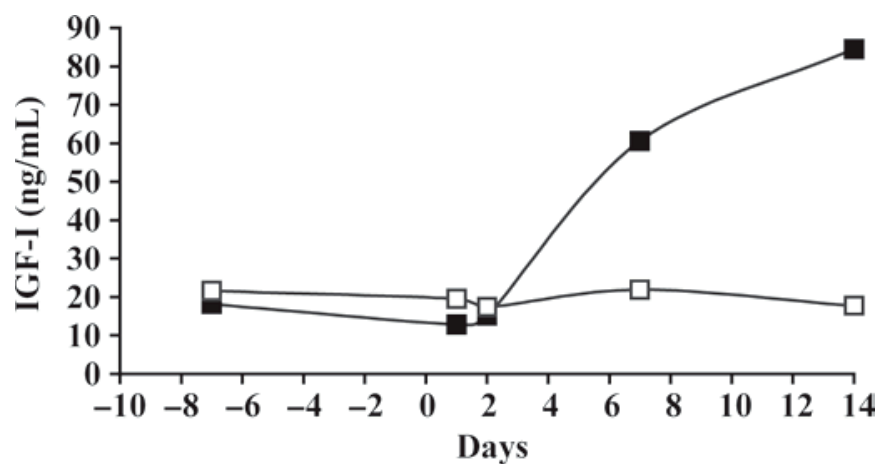

Figure 4. IGF-I concentration in milk from nonmilked (ם) or milked $(\square)$ quarters. Value 0 on time scale refers to drying off. Data are presented as least squares means with SEM $<1.99$. 


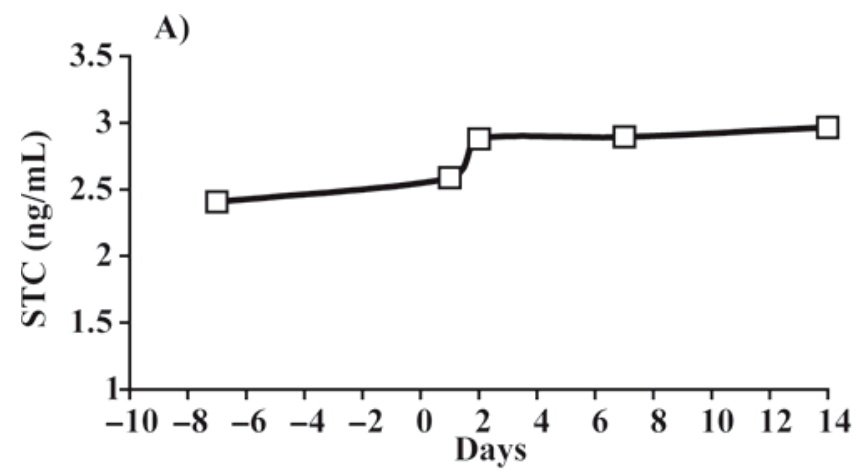

B)

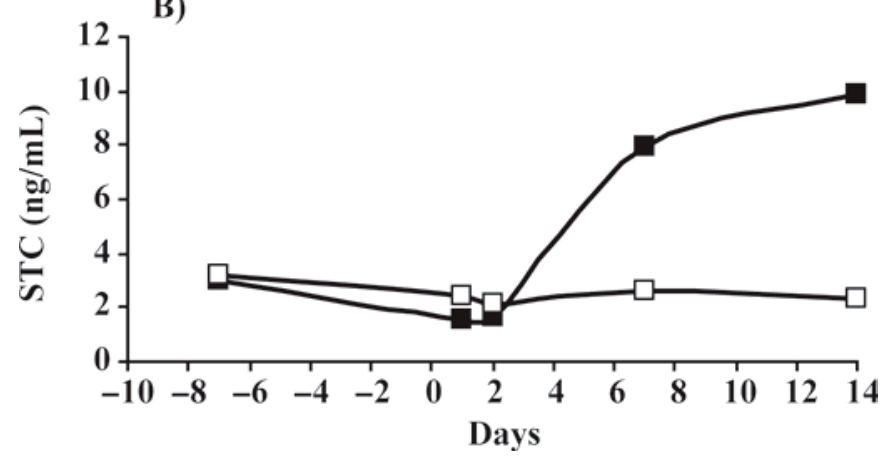

Figure 5. STC-1 concentration in serum (A) and milk (B) from nonmilked $(\mathbf{\square})$ or milked $(\square)$ quarters. Value 0 on time scale refers to drying off. Data are presented as least squares means. A (SEM < $0.024)$, B $($ SEM $<0.093)$.

involves local and individual regulation of the quarters. This hypothesis is supported by previous results showing that a decrease in milk production was accompanied by an increase in milk concentrations of STC-1 (Delbecchi et al., 2005; Miller et al., 2006). Although direct proof is still lacking, the results presented suggest that STC-1 is an effector of the involution process.

In female rats, the STC-1 found in the mammary gland during lactation was apparently of endocrine origin. In that species, STC-1 expression by the mammary gland was very low during lactation and involution, but high during gestation (Hasilo et al., 2005). Because of the substantial heterogeneity of the tissues obtained from cows in late lactation, we were not able to report expression data for STC-1 during milk stasis (data not presented). Nevertheless, because the concentration of STC-1 in milk correlated with the concentration of BSA, which is an indicator of increasing TJ permeability, one possible scenario is that STC-1 found in milk originated in the serum. On the other hand, the STC-1 levels in milk were approximately $10 \mathrm{ng} /$ $\mathrm{mL}$, whereas those in blood did not exceed $3 \mathrm{ng} / \mathrm{mL}$. If the STC-1 entered the gland following TJ opening, the STC-1 levels should not have exceeded those in the blood. This finding calls into question the possible serum origin of STC-1 in milk. Delbecchi et al. (2005) reported that estradiol administration to dairy cows increased mammary gland STC-1 mRNA levels and the protein concentration of milk while reducing overall milk production, a finding that supports the mammary origin of the STC-1 found in milk. Therefore, the most likely scenario is that the STC-1 gene was upregulated in the involuting mammary gland, as already suggested by Delbecchi et al. (2005), resulting in higher milk levels of the hormone.

Matrix metalloproteinases are involved in the remodeling of the bovine mammary gland, although their exact role during involution is still poorly characterized. Through zymogram analysis, 2 gelatinases that varied significantly in the milk of all the cows were highlighted. Similar MMP patterns have been reported in the milk from healthy glands (Mehrzad et al., 2005; Miller et al., 2006). Based on their molecular weight and on results from Raulo et al. (2002), we propose that these major proteinases are MMP-2 and MMP-9. In addition to these MMP, some cows presented distinct banding patterns of minor MMP. The zymography results obtained by Mehrzad et al. (2005) in blood or immune cells isolated from mastitis-affected quarters demonstrated similar banding patterns. Other studies reported that the proteolytic activity in milk came from neutrophils that express MMP-9 (Li et al., 1999). The proteinase patterns found in the various cows could be explained by the state of opening of the TJ at the start of treatment as well as by the populations of immune cells that are present. The importance of STC-1 to the increase in proteinase activities is unknown. If STC-1 affects TJ fence function, it might affect the pattern of proteinase activity. One recent report indicated that STC can modulate the trans-endothelial migration of leukocytes (Chakraborty et al. 2007). No information is available concerning the action of STC-1 on bovine leukocytes,

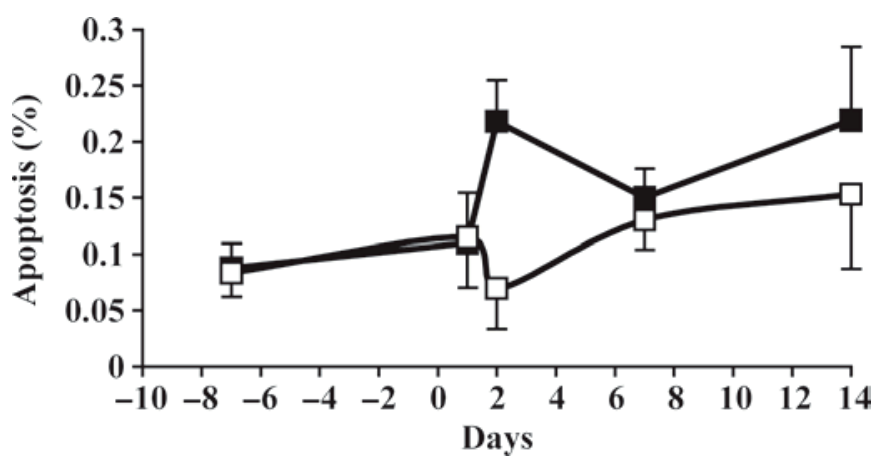

Figure 6. Detection by terminal deoxynucleotidyl transferase-mediated dUTP nick-end labeling of apoptotic cells in mammary biopsies taken from milked $(\square)$ or nonmilked $(\square)$ quarters. Value 0 on time scale refers to drying off. Results are given as the percentage of apoptotic cells/total cells and data are presented as least squares means \pm SEM. 
Table 1. Spearman correlation coefficients among different factors in milk and in cellular activity of mammary glands that were milked or not milked unilaterally for $14 \mathrm{~d}$

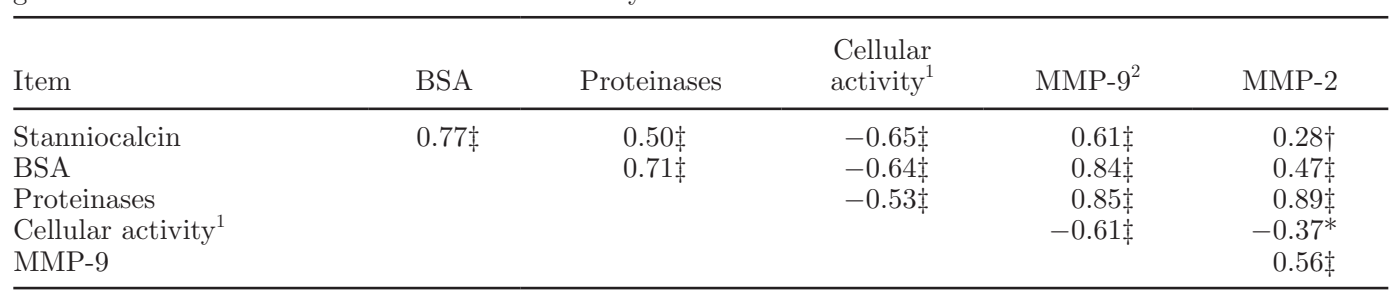

${ }^{1}$ Measured by turnover of the tetrazolium salt XTT, 23-bis-(2-methoxy-4-nitro-5-sulfophenyl)-2H-tetrazolium5-carboxanilide.

${ }^{2} \mathrm{MMP}=$ matrix metalloproteinase.

$* P<0.05 ; \dagger P<0.01 ; \ddagger P<0.001$

but if such an interaction occurs, then it should affect the proteinase patterns of milk. The exact contribution of STC-1 to the proteinase phase of involution remains to be clarified.

Several reports have indicated that milk may contain a feed-back regulator of lactation. But, this factor is still hypothetical and has never been clearly identified.
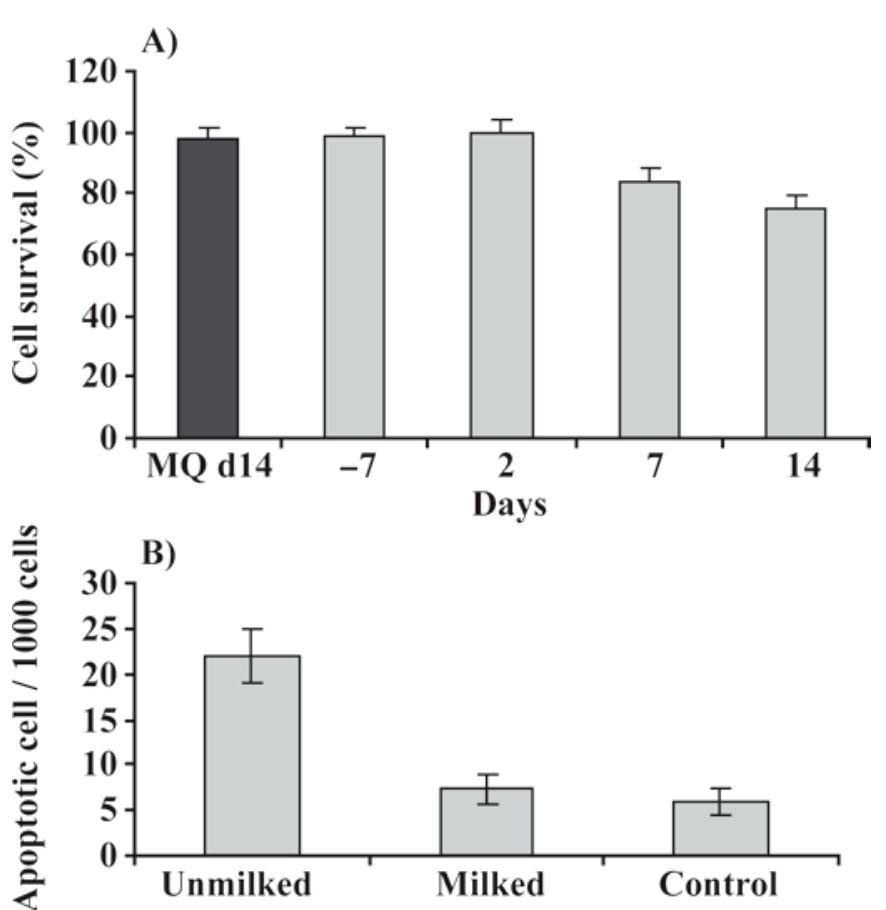

Figure 7. Effect of milk from milked or nonmilked quarters on mammary epithelial (MAC-T) cells. A) Cellular activity following a 10-h incubation of MAC-T cells with milk from milked (black bar) or nonmilked (gray bars) quarters at different times following drying off, as measured by the reduction of the tetrazolium salt, XTT, 23-bis(2-methoxy-4-nitro-5-sulfophenyl)-2H-tetrazolium-5-carboxanilide. Cellular activity is given as the ratio (\%) between optical density at $450 \mathrm{~nm}$ obtained by dividing the treatment values by the control values without milk. Time scale refers to drying off on d 0 . B) The number of apoptotic cells following incubation with pooled milk from milked or nonmilked quarters. Control cells were incubated without milk. Data presented in A are unadjusted means \pm SEM and in B, unadjusted means \pm SEM. MQ $=$ milked quarters.
To assess this hypothesis, we used MAC-T cells to test the effects of milk from involuting quarters on their metabolic state. We demonstrated that the metabolic rate of MAC-T cells was reduced following the addition of milk from involuting quarters. TUNEL assay showed that milk from involuting quarters increased apoptosis. Milk from dried-off quarters can increase or decrease the synthesis of DNA in cell cultures (Sejrsen et al., 2001). Milk obtained from nonmilked quarters contained more IGF-I than that from milked quarters, suggesting that the increase in apoptosis was not caused by the loss of this survival factor.

The biological function of STC-1 during involution is unknown. Using a cellular assay with milk containing different levels of STC-1, a negative correlation was obtained between the cellular metabolic rate and the STC-1 concentration $(-0.65 ; P<0.0001)$. A negative correlation was observed between metabolic rate and the proteinase concentration in milk $(-0.53 ; P<0.0003)$. This result suggests that milk-derived STC- 1 could be a factor that decreases cellular activity. Nonetheless, STC-1 is known to target mitochondria to increase electron transport chain activity (Ellard et al., 2007), a result which is counter to our correlation. However, as STC-1 is only one of many factors that are increased in milk during involution, its exact role in mammary cell function during the involution process remains to be determined.

Stanniocalcin-1 can apparently act as a pro- or antiapoptotic factor. The TUNEL assays on mammary biopsies indicated that apoptosis increased transitorily to peak values at $d 2$. In vitro, we found that apoptosis increased by 3 -fold for cells incubated with milk from quarters that had been unmilked for $14 \mathrm{~d}$. Such biological processes depend on the balance between effectors and repressors, and here we have shown that milk contains factors that are capable of inducing apoptosis, yet in vivo, the balance between these effectors and growth factors leads to survival.

Serum STC-1 levels increased during the treatment period. Such endocrine data are always difficult to in- 
terpret because of the mixed effects of different factors. While STC-1 concentrations increased we obtained an increase in milk production for 2 quarters and involution of the 2 others. In lactating mice, serum STC-1 was presumed of ovarian origin, and its expression was dependent on the suckling stimulus, perhaps mediated by the action of prolactin (Deol et al., 2000). Thus, it is possible that milked quarters influenced endocrine STC-1, although this effect of milking on STC-1 remains to be clarified. The loss of TJ function could have opened a way for the intraalveolar STC-1 to reach the circulation and contribute to bloodborne STC-1. The exact origin of endocrine STC-1 during drying off remains to be clarified.

In summary, by using a unilateral milking model on cows, we induced involution of 2 quarters while the others were still being milked. This enabled us to evaluate variations in STC-1 levels in serum and milk and the progression of involution markers. There was a transitory increase in apoptosis in the first days following milk stasis, and an increase in proteinase activity and BSA that correlated with the STC-1 levels in milk. Moreover, the in vitro results showed a correlation between STC-1 and a reduction of cellular metabolism, perhaps by apoptosis. These results suggest that STC-1 is implicated in the progression of involution. Nevertheless, more research will be needed to determine the target and function of this hormone during involution.

\section{ACKNOWLEDGMENTS}

The authors thank several people from the Dairy and Swine R\&D Centre including Jasmin Brochu, Benoit Pouliot, and Lena Core for technical assistance, the dairy barn staff for taking care of the cows, and Steve Méthot for performing the statistical analysis. This research was financially supported by The Dairy Farmers of Canada, Agriculture and Agri-food Canada, the National Science and Engineering Council of Canada and The Canadian Institutes of Health Research.

\section{REFERENCES}

Abribat, T., P. Brazeau, I. Davignon, and D. R. Garrel. 1993. Insulinlike growth factor-I blood levels in severely burned patients: Effects of time post injury, age of patient and severity of burn. Clin. Endocrinol. (Oxf.) 39:583-589.

Bouchard, L., S. Blais, C. Desrosiers, X. Zhao, and P. Lacasse. 1999. Nitric oxide production during endotoxin-induced mastitis in the cow. J. Dairy Sci. 82:2574-2581.

Capuco, A. V., R. M. Akers, and J. J. Smith. 1997. Mammary growth in Holstein cows during the dry period: Quantification of nucleic acids and histology. J. Dairy Sci. 80:477-487.

Chakraborty, A., H. Brooks, P. Zhang, W. Smith, M. R. McReynolds, J. B. Hoying, R. Bick, L. Truong, B. Poindexter, H. Lan, W. Elbjeirami, and D. Sheikh-Hamad. 2007. Stanniocalcin-1 regulates endothelial gene expression and modulates transendothelial migration of leukocytes. Am. J. Physiol. Renal Physiol. 292:895904.

Delbecchi, L., N. Miller, C. Prud'homme, D. Petitclerc, G. F. Wagner, and P. Lacasse. 2005. 173-Estradiol reduces milk synthesis and increases stanniocalcin gene expression in the mammary gland of lactating cows. Livest. Prod. Sci. 98:57-66.

Deol, H. K., R. Varghese, G. F. Wagner, and G. E. Dimattia. 2000. Dynamic regulation of mouse ovarian stanniocalcin expression during gestation and lactation. Endocrinology 141:3412-3421.

Dodier, P., and A. Piche. 2006. Bcl-X(L) is functionally non-equivalent for the regulation of growth and survival in human ovarian cancer cells. Gynecol. Oncol. 100:254-263.

Ellard, J. P., C. R. McCudden, C. Tanega, K. A. James, S. Ratkovic, J. F. Staples, and G. F. Wagner. 2007. The respiratory effects of stanniocalcin-1 (STC-1) on intact mitochondria and cells: STC-1 uncouples oxidative phosphorylation, and its actions are modulated by nucleotide triphosphates. Mol. Cell. Endocrinol. 264:90-101.

Flik, G., F. Rentier-Delrue, and S. E. Wendelaar Bonga. 1994. Calcitropic effects of recombinant prolactins in Oreochromis mossambicus. Am. J. Physiol. 266:R1302-R1308.

Hamann, J., and P. Gyodi. 1994. Effects on milk yield, somatic cell count and milk conductivity of short-term non-milking of lactating quarters of cows. J. Dairy Res. 61:317-322.

Hasilo, C. P., C. R. McCudden, J. R. Gillespie, K. A. James, E. R. Hirvi, D. Zaidi, and G. F. Wagner. 2005. Nuclear targeting of stanniocalcin to mammary gland alveolar cells during pregnancy and lactation. Am. J. Physiol. Endocrinol. Metab. 289:E634E642.

Kleiner, D. E., and W. G. Stetler-Stevenson. 1994. Quantitative zymography: Detection of picogram quantities of gelatinases. Anal. Biochem. 218:325-329.

Lauzon, K., X. Zhao, and P. Lacasse. 2006. Deferoxamine reduces tissue damage during endotoxin-induced mastitis in dairy cows. J. Dairy Sci. 89:3846-3857.

Li, X., X. Zhao, and S. Ma. 1999. Secretion of $92 \mathrm{kDa}$ gelatinase (MMP-9) by bovine neutrophils. Vet. Immunol. Immunopathol. $67: 247-258$.

Lund, L. R., J. Romer, N. Thomasset, H. Solberg, C. Pyke, M. J. Bissell, K. Dano, and Z. Werb. 1996. Two distinct phases of apoptosis in mammary gland involution: Proteinase-independent and -dependent pathways. Development 122:181-193.

Madsen, K. L., M. N. Tavernini, C. Yachimec, D. L. Mendrick, P. J. Alfonso, M. Buergin, H. S. Olsen, M. J. Antonaccio, A. B Thomson, and R. N. Fedorak. 1998. Stanniocalcin: A novel protein regulating calcium and phosphate transport across mammalian intestine. Am. J. Physiol. 274:G96-G102.

Mehrzad, J., C. Desrosiers, K. Lauzon, G. Robitaille, X. Zhao, and P. Lacasse. 2005. Proteases involved in mammary tissue damage during endotoxin-induced mastitis in dairy cows. J. Dairy Sci. $88: 211-222$.

Miller, N., L. Delbecchi, D. Petitclerc, G. F. Wagner, B. G. Talbot, and P. Lacasse. 2006. Effect of stage of lactation and parity on mammary gland cell renewal. J. Dairy Sci. 89:4669-4677.

Niu, P., D. P. Radman, E. M. Jaworski, H. Deol, R. Gentz, J. Su, H. S. Olsen, and G. F. Wagner. 2000. Development of a human stanniocalcin radioimmunoassay: Serum and tissue hormone levels and pharmacokinetics in the rat. Mol. Cell. Endocrinol. 162:131144.

Rabot, A., F. Sinowatz, B. Berisha, H. H. Meyer, and D. Schams. 2007. Expression and localization of extracellular matrixdegrading proteinases and their inhibitors in the bovine mammary gland during development, function, and involution. J. Dairy Sci. 90:740-748.

Raser, K. J., A. Posner, and K. K. Wang. 1995. Casein zymography: A method to study mu-calpain, m-calpain, and their inhibitory agents. Arch. Biochem. Biophys. 319:211-216.

Raulo, S. M., T. Sorsa, T. Tervahartiala, T. Latvanen, E. Pirila, J. Hirvonen, and P. Maisi. 2002. Increase in milk metalloproteinase activity and vascular permeability in bovine endotoxin-induced and naturally occurring Escherichia coli mastitis. Vet. Immunol. Immunopathol. 85:137-145. 
Sejrsen, K., L. O. Pedersen, M. Vestergaard, and S. Purup. 2001. Biological activity of bovine milk - Contribution of IGF-1 and IGF binding proteins. Livest. Prod. Sci. 70:79-85.

Sorensen, M. T., J. V. Norgaard, P. K. Theil, M. Vestergaard, and K. Sejrsen. 2006. Cell turnover and activity in mammary tissue during lactation and the dry period in dairy cows. J. Dairy Sci. 89:4632-4639.

Stelwagen, K., V. C. Farr, H. A. McFadden, C. G. Prosser, and S. R Davis. 1997. Time course of milk accumulation-induced opening of mammary tight junctions, and blood clearance of milk components. Am. J. Physiol. 273:R379-R386.

Varghese, R., A. D. Gagliardi, P. E. Bialek, S. P. Yee, G. F. Wagner, and G. E. Dimattia, 2002. Overexpression of human stanniocalcin affects growth and reproduction in transgenic mice. Endocrinology $143: 868-876$
Varghese, R., C. K. Wong, H. Deol, G. F. Wagner, and G. E. DiMattia 1998. Comparative analysis of mammalian stanniocalcin genes. Endocrinology 139:4714-4725.

Wagner, G. F., C. C. Guiraudon, C. Milliken, and D. H. Copp. 1995 Immunological and biological evidence for a stanniocalcin-like hormone in human kidney. Proc. Natl. Acad. Sci. USA 92:18711875 .

Wheelock, J. V., A. Smith, F. H. Dodd, and R. L. J. Lyster. 1967. Changes in the quantity and composition of mammary gland secretion in the dry period between lactations. 1. The beginning of the dry period. J. Dairy Res. 34:1-12.

Zaidi, D., K. A. James, and G. F. Wagner. 2006. Passive immunization of lactating mice with stanniocalcin-1 antiserum reduces mammary gland development, milk fat content, and postnatal pup growth. Am. J. Physiol. Endocrinol. Metab. 291:E974-E981. 